\title{
Efeito da luz na germinação e desenvolvimento de plântulas de pinhão-manso (Jatropha curcas $L$.) de distintas procedências
}

\author{
Fernanda Juliana da Silva ${ }^{1}$, Erika Yano Hisatugo² e João Paulo de Souza ${ }^{3,4}$
}

Recebido: 26.10.2015; aceito: 1.03.2016

\begin{abstract}
Light effects on germination and early development of physic nut (Jatropha curcas L.) from distinct geographical provenances). Studies about the influence of light on the germination and early development are important to cultivate physic nut in the field. The aim of this study was to evaluate the light effect on the seed germination of physic nuts from distinct geographical provenances and to examine the morphology of seedlings. The first germination bioassay was accomplished in a dark chamber and the second in the presence of light $\left(32 \mu \mathrm{mol} \mathrm{m}^{-2} \mathrm{~s}^{-1}\right)$ with a daily photoperiod of 12 hours. There was no significant difference in the percentage of seed germination between of the seeds of the studied lots. The percentage of germination was high in all lots (in the dark or under light), being the seeds classified as neutral photoblastic. In the dark, the seedlings had a greater number of emerged and opened cotyledons, length of hypocotyl-root axis, and growth rate. These results are explained by etiolation of seedlings, germinated in the dark. However, under the light, there was a darkening of seedlings, which impaired impairing its development.
\end{abstract}

Keywords: germinability, light, seedling morphology

RESUMO - (Efeito da luz na germinação e desenvolvimento inicial de plântulas de pinhão-manso (Jatropha curcas L.) de distintas procedências). Estudos sobre a influência da luz na germinação e desenvolvimento inicial são importantes para o cultivo de pinhão-manso em campo. O objetivo desse trabalho foi avaliar o efeito da luz na germinação de sementes de pinhão-manso de distintas procedências e examinar a morfologia das plântulas. O primeiro bioensaio de germinação foi realizado em câmara escura e o segundo na presença de luz $\left(32 \mu \mathrm{mol} \mathrm{m}^{-2} \mathrm{~s}^{-1}\right)$ com um fotoperíodo diário de 12 horas. Não houve diferença significativa na porcentagem de germinação entre as sementes dos lotes estudados. A porcentagem de germinação em todos os lotes foi alta, na presença ou não de luz, sendo as sementes classificadas como fotoblásticas neutras. No escuro, as plântulas apresentaram maior número de cotilédones surgidos e abertos, comprimento do eixo hipocótilo-radicular e velocidade de crescimento. Esses resultados são explicados pelo estiolamento das plântulas germinadas no escuro. Porém, sob luz houve escurecimento das plântulas comprometendo seu desenvolvimento.

Palavras-chave: germinabilidade, luz, morfologia da plântula

\section{Introdução}

O pinhão-manso (Jatropha curcas L., Euphorbiaceae) é uma planta com multiusos, tanto econômicos quanto medicinais (Gübitz et al. 1999, Openshaw 2000, Augustus et al. 2002, Tiwari et al. 2007). Destacam-se como usos econômicos, a utilização no controle da erosão do solo (Heller 1996), na produção de óleo extraído de suas sementes (Tiwari et al. 2007) e formação de cercas em plantações, por ser tóxica para animais (Heller 1996). O óleo extraído das sementes também pode ser utilizado para produção de sabão e combustível para lâmpadas (Gübtiz et al. 1999). Como usos farmacêuticos destacam-se a utilização do látex com fins curativos, hemostáticos e purgativos (Peixoto 1973). Apresenta hábito arbóreo, podendo atingir até cinco metros de altura. Pinhãomanso é originário do México e América Central,

1. Universidade Federal de Viçosa, Instituto de Ciências Biológicas e Saúde, campus Florestal, Curso de Ciências Biológicas, Rodovia LMG 818, Km 6, campus Universitário s/n, 35690-000 Viçosa, MG, Brasil

2. Secretaria Municipal de Educação de Uberlândia, Escola Municipal Professora Orlanda Neves Strack, Rua da Produção, 1675, 38402172 Uberlândia, MG, Brasil

3. Universidade Federal de Viçosa, Instituto de Ciências Biológicas e da Saúde, Campus Florestal, Rodovia LMG 818, Km 6, campus Universitário, s/n 35690-000 Viçosa, MG, Brasil

4. Autor para correspondência: joaopaulobio@hotmail.com 
porém é cultivado em diversos lugares do mundo (Putten et al. 2010). Cresce em ampla faixa de regime hídrico (200 - $1500 \mathrm{~mm}$ ), ocorrendo queda das folhas quando submetido a longos períodos de seca (Gübtiz et al. 1999). Por outro lado, de acordo com o aumento do regime de chuvas, as plantas de pinhão-manso aumentam a produtividade primária líquida (Gübtiz et al. 1999, Openshaw 2000).

O estudo da germinação de sementes contribui para a propagação e melhor planejamento para o estabelecimento das espécies vegetais (Melo \& Varela 2006). Em adição, a morfologia da plântula permite caracterizar famílias, gêneros e até mesmo espécies (Ferraz 1991, Oliveira 1993), além de auxiliar em estudos de ecologia da espécie e interpretação dos testes de germinação realizados em laboratório (Oliveira 1993). No teste de germinação, de acordo com as Regras para Análise de Sementes (Ministério da Agricultura 2009), considera-se germinada toda semente que, pela emergência e desenvolvimento das estruturas essenciais de seu embrião, demonstra aptidão para produzir uma planta normal sob condições normais e favoráveis de campo.

A quebra da dormência das sementes pode ocorrer por um fator ou a combinação de fatores como intensidade luminosa, temperatura ótima e umidade do substrato (Kyereh et al. 1999). A influência da luz na germinação e estabelecimento inicial de plântulas tem sido foco de diversos estudos (Matos et al. 2009, Bandeira et al. 2011, Lopes et al. 2005), sendo de grande importância, pois possibilita o sucesso na produção de mudas e diminui as perdas de plantas na fase inicial de cultivo.

As condições intrínsecas (dormência das sementes) e extrínsecas (ambientais) afetam o processo de germinação das sementes (Bewley \& Black 1994). Em pinhão-manso, pouco se sabe sobre métodos de obtenção e armazenamento corretos de frutos para a obtenção de mudas, o que dificulta a produção em larga escala. O estudo do processo reprodutivo, como germinação, morfologia de frutos, sementes e plântulas, gera subsidio para a produção de mudas (Zamith \& Scarano 2004), compreensão do estabelecimento das plântulas em condições de laboratório (Matheus \& Lopes 2007) e para a inclusão da espécie em futuros manuais técnicos. Os estudos da qualidade genética, física, fisiológica e sanitária das sementes de diferentes populações devem ser observados e relacionados à germinação e desenvolvimento inicial das plântulas (Höfs et al. 2004, Vanzolini et al. 2010). Essas informações ajudarão no melhor aproveitamento por parte de produtores no estabelecimento de mudas e plantio em campo.

Assim, o objetivo do presente trabalho foi verificar a influência da luz na germinação de sementes de pinhão-manso oriundas de distintas procedências, visando obter a melhor condição de luminosidade para a germinação das sementes. Em adição, descrevemos a morfologia da plântula, desde a germinação até o aparecimento dos cotilédones, com o objetivo de auxiliar futuros estudos de ecofisiologia dessa espécie.

\section{Material e métodos}

O estudo foi realizado no Laboratório de Cultura de Tecidos Vegetais localizado no setor de fruticultura da Universidade Federal de Viçosa (UFV), Campus Florestal, durante os meses de novembro de 2010 a fevereiro de 2011. As sementes de pinhão-manso utilizadas foram obtidas da empresa SADABioenergia e Agricultura LTDA, proveniente de três lotes diferentes: SADA JCL 01, SADA JCL 02 e SADA JCL 03, sendo os dois primeiros nativos de províncias do México e o último do Brasil (cidade de Jaíba, MG). Um quarto lote foi doado pela UFV, Campus Viçosa, com sementes oriundas da cidade de Janaúba, MG. Todos os quatro lotes ficaram armazenados em sacos plásticos pretos, à temperatura de $25^{\circ} \mathrm{C}$ e protegidos da luz. De cada lote foram formados grupos contendo 100 sementes.

As sementes foram lavadas e tratadas com solução a $2 \%$ de hipoclorito de sódio por dois minutos para a eliminação de microrganismos patogênicos e enxaguadas abundantemente, para retirada do produto (Ministério da Agricultura 2009).

As sementes foram distribuídas sobre uma folha do papel de germinação, embebida em água destilada, com o ventre voltado para o papel e a carúncula direcionada para baixo. As sementes foram recobertas por outra folha de papel de germinação previamente umedecida. As 100 sementes foram distribuídas em oito rolos de papel e colocadas em recipiente plástico contendo água destilada. Esse mesmo procedimento foi repetido para cada lote. Os recipientes contendo os rolos com sementes foram colocados na câmara de germinação tipo B.O.D. (Nova ética, modelo 411-FPD/155) à temperatura aproximada de $30{ }^{\circ} \mathrm{C}$ (Tagliani \& Ribas 2009).

Dois bioensaios de germinação foram realizados, o primeiro em câmara escura e o segundo na presença de luz controlada pela própria câmara de germinação 
mantendo um fotoperíodo diário de 12 horas a uma intensidade de $32 \mu \mathrm{mol} \mathrm{m} \mathrm{m}^{-2} \mathrm{~s}^{-1}$.

O desenvolvimento das sementes foi acompanhado desde o $1^{\circ}$ até o $14^{\circ}$ dia. Devido ao fato do manual de Regra de Análise de Sementes (Ministério da Agricultura 2009) não especificar tempo para a contagem de sementes germinadas de pinhão manso, a última contagem foi realizada aos 14 dias que é o período mais indicado para outras oleaginosas similares, incluindo a mamona (Ricinus communis L.). O experimento prosseguiu mesmo após a emissão da radícula, pois, para fim de produção de mudas a germinação só é considerada quando resulta em plântulas normais. Durante esse período foram avaliados os seguintes parâmetros: emissão da radícula, número de raízes, tamanho da plântula (eixo hipocótilo-radicular medido abaixo dos cotilédones até a ponta da maior raiz), dia em que os cotilédones se separaram da carúncula, dia que os cotilédones se abriram, velocidade média de germinação, velocidade de crescimento e número de plântulas mortas. Para fazer as medições foram tomadas sempre as duas primeiras sementes de cada rolo.

Os resultados de germinação, obtidos em porcentagem, foram transformados em arco seno da raiz quadrada de $\times / 100$. A porcentagem de germinação, velocidade de germinação, média do comprimento do eixo hipocótilo radicular, número de cotilédones surgidos, número de cotilédones abertos, número médio de raízes, número de plântulas mortas e velocidade de crescimento foram submetidos à análise de variância, com a comparação das médias pelo teste de Tukey, a 5\% de probabilidade (Zar 1999), para verificarmos as possíveis diferenças entre os lotes de sementes. Para verificarmos o efeito da luz sobre os parâmetros da germinação avaliados, foi aplicado o teste de t de Student (Zar 1999).

\section{Resultados}

Comparação entre os lotes na ausência de luz Constatou-se que a porcentagem média de germinação, velocidade média de germinação (sementes/dia), plântulas mortas e número médio de raízes por plântula não diferiram significativamente entre os distintos lotes (tabela 1). A média do comprimento do eixo hipocótilo-radicular e a velocidade de crescimento ( $\mathrm{cm} /$ dia) no lote Sada JCL 02 foi superior ao lote Sada JCL 01, não diferindo significativamente dos outros lotes (tabela 1). Em adição, as sementes dos lotes Janaúba e Sada JCL 02 apresentaram maior número de cotilédones emergidos e abertos (tabela 1).

Comparação entre os lotes na presença de luz - No experimento na presença de luz a porcentagem de germinação, velocidade de germinação, comprimento do eixo hipocótilo-radicular, número de cotilédones abertos, número de raízes e velocidade de crescimento foram semelhantes nas sementes dos quatro lotes estudados (tabela 1). O número de cotilédones emergidos no lote Sada JCL 01 foi inferior aos demais, enquanto o número de plântulas mortas diferiu apenas entre os lotes Janaúba (maior mortalidade) e Sada JCL 01 (menor mortalidade, tabela 1).

Na presença de luz houve uma maior similaridade entre os parâmetros analisados na germinação dos quatro lotes de sementes de pinhão-manso (tabela 1), o que não ocorreu na ausência de luz (tabela 1).

Comparação do experimento de germinação na presença e na ausência de luz - Na comparação dos lotes na presença e ausência de luz foram encontradas maiores diferenças dos parâmetros da germinação estudados (tabela 1). A velocidade de crescimento das plântulas (cm/dia) e o comprimento do eixo hipocótilo-radicular foram maiores em todos os lotes de sementes na ausência de luz (tabela 1). A porcentagem de cotilédones emergidos na ausência de luz foi maior nos lotes Janaúba e Sada JCL 02, enquanto a porcentagem de cotilédones abertos foi maior em todos os lotes na ausência de luz exceto no lote Sada JCL 03. Por outro lado, o número de plântulas mortas foi maior na presença de luz em todos os lotes (tabela 1). A porcentagem de germinação, velocidade de germinação e número de raízes foi semelhante em todos os lotes de sementes na presença e ausência de luz (tabela 1). Porém, a luz afetou o crescimento inicial das plântulas ao decorrer do tempo, principalmente a partir do $4^{\circ}$ dia, quando o eixo do hipocótilo apresentou pontos de necrose resultando posteriormente na perda de muitas plântulas.

Morfologia da plântula - A germinação de pinhãomanso é epígea, fanerocotiledonar e as sementes apresentam fotoblastismo neutro. Após quatro dias verificou-se a protrusão da radícula nas sementes dos quatro lotes e nos dois regimes de luz (com luz e na ausência de luz, figura 1). A radícula apresentou coloração branca nas sementes dos quatro lotes. A raiz primária axial apresentou quatro primórdios de raízes secundárias nas sementes de todos os lotes (com e sem luz). O coleto é bem definido nas 


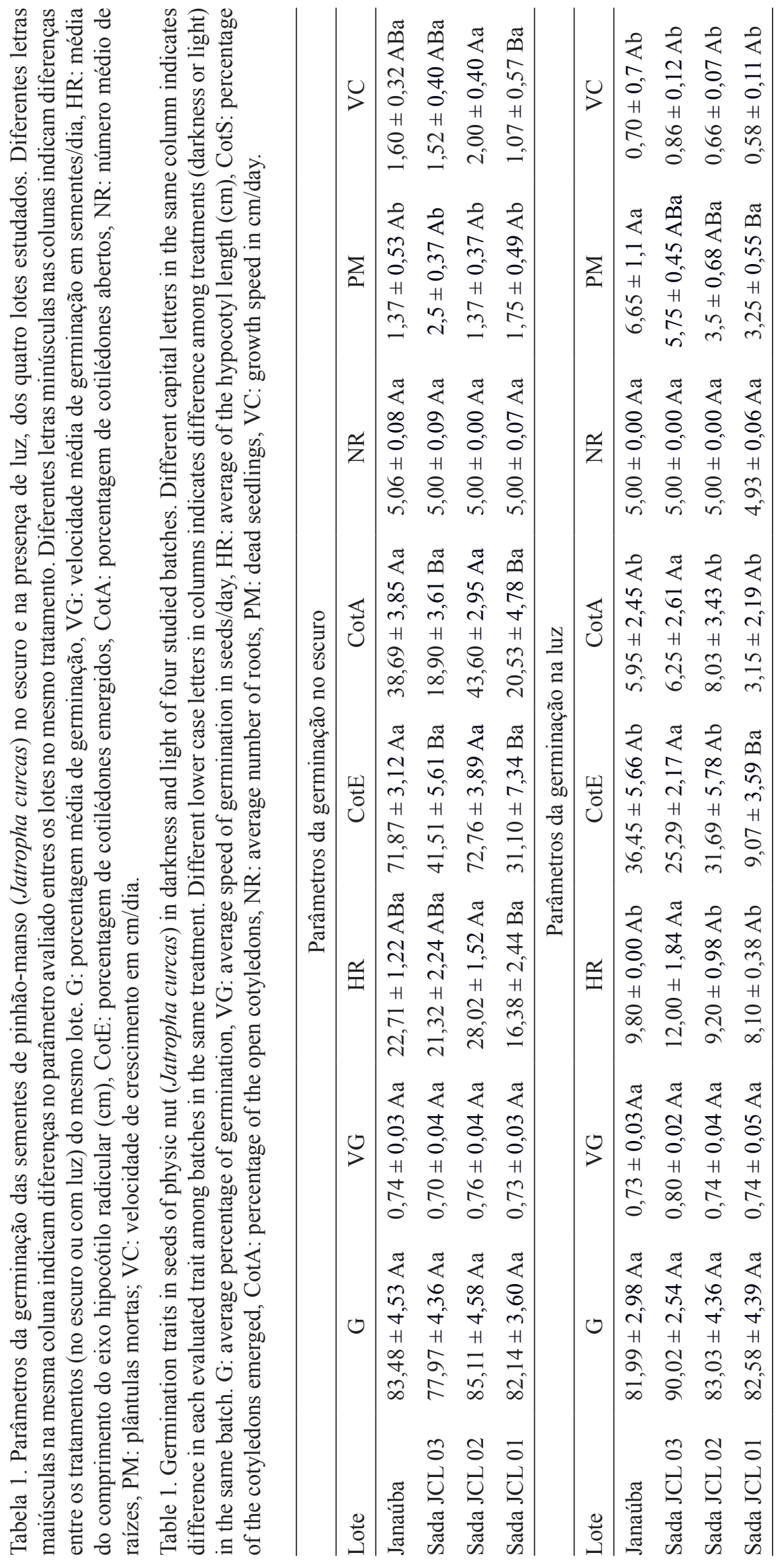


plântulas germinadas sob luz pela evidente mudança de coloração do hipocótilo (esverdeada) para as raízes (esbranquiçadas). Entretanto, o coleto nas plântulas germinadas na ausência de luz não apresentou coloração diferenciada, existindo diferença clara entre o diâmetro do hipocótilo e raiz primária. No experimento sem luz os cotilédones surgiram no sexto dia nas sementes de todos os lotes e no experimento com luz os cotilédones surgiram no oitavo dia nas sementes dos quatro lotes. Os cotilédones (dois) são opostos, glabros e não carnosos (figura 1). O hipocótilo apresentou formato cilíndrico e glabro nas sementes dos quatro lotes estudados. No experimento sem luz o meristema apical caulinar das plântulas começou a produzir os protófilos no $11^{\circ}$ dia após a montagem do experimento. Porém, no experimento com luz não foi observado produção de protófilos até o fim do experimento (14 dias).

\section{Discussão}

O tempo médio de germinação das sementes de pinhão-manso é de dois dias considerando o surgimento da radícula, esse fato pode ser observado nos dois testes de germinação desse estudo (com e sem luz). O endosperma dessas sementes de pinhãomanso, rico em óleo (Nunes et al. 2009), supre as necessidades iniciais do embrião (Ferri 1983) e é totalmente consumido na germinação. A embebição aumenta o volume da semente causando a ruptura do tegumento próximo à região micropilar (Nunes et al. 2009, Añez et al. 2005). No experimento com as sementes de pinhão-manso (com e sem luz) foi observado que a plântula se desprendeu totalmente do tegumento a partir do $4^{\circ}$ dia de germinação.

Comparando os distintos lotes de sementes, foram observadas pequenas diferenças nos parâmetros avaliados tanto no experimento de germinação com luz como na ausência de luz. As sementes de espécies oleaginosas devem ser armazenadas em ambiente com umidade relativa e temperatura mais baixa devido a pouca estabilidade química dos lipídeos (Fanan et al. 2009). Para sementes de mamona, que também pertence à família Euphorbiaceae, sementes armazenadas por até um ano não têm sua qualidade consideravelmente afetada (Fanan et al. 2009). A porcentagem média de germinação encontrada para as sementes de pinhão-manso (77\%) é considerada alta, sendo que essas sementes estavam armazenadas por cerca de um ano, em temperatura ambiente, protegidas de luz e umidade. Resultados semelhantes foram encontrados por Vanzolini et al. (2010) e Martins et al. (2008), onde as sementes de pinhãomanso apresentaram germinação entre 70 e $87 \%$. É importante um armazenamento adequado para que a qualidade fisiológica das sementes seja preservada e a alta porcentagem de germinação seja mantida.

A porcentagem e a velocidade de germinação foram semelhantes na comparação do experimento com luz e na ausência de luz dentro de cada lote. Isso é comum em plantas cujas sementes possuem fotoblastismo neutro. Essa característica é importante, explicando a ampla distribuição geográfica do pinhãomanso nas regiões de clima tropical, sendo a espécie nativa da América Central e adaptada em partes tropicais e subtropicais da Ásia e África (Augustus et al. 2002, Loureiro et al. 2007, Nery et al. 2009). A falta da influência da luz no processo germinativo pode estar relacionada à capacidade do pinhão-manso em germinar desde as bordas a sol pleno, até o interior de florestas, sob o dossel (Rossatto \& Kolb 2010).

No entanto, a luz afetou o crescimento inicial das plântulas, no decorrer do tempo, principalmente a partir do $4^{\circ}$ dia, quando o eixo hipocótilo-radicular apresentou pontos escuros resultando posteriormente na morte de muitas plântulas. Segundo Melo et al. (2001), em estudo realizado com plântulas de guariroba, a luz acelera a biossíntese e a oxidação de compostos fenólicos o que causa o escurecimento dos tecidos e compromete o desenvolvimento das plântulas. Existem formas de evitar esse escurecimento causado pela ação oxidativa, como a redução do fotoperíodo e o controle da umidade no interior da câmara. Um estudo mais aprofundado enfocando o escurecimento e morte das plântulas é importante, pois poderia resultar na diminuição da perda da produção. Devido à morte de muitas plântulas, o experimento com luz também apresentou menor porcentagem de cotilédones emergidos e abertura dos cotilédones.

O hipocótilo nas plântulas de pinhão-manso é bem desenvolvido, como acontece em plantas com germinação epígea (Guerreiro \& Gloria 2003). Quanto ao crescimento do eixo hipocótilo-radicular, as plântulas na ausência de luz apresentaram maior velocidade de crescimento ( $\mathrm{cm} / \mathrm{dia})$ e maior comprimento final $(\mathrm{cm})$. O maior investimento no crescimento em altura em ambientes não iluminados é uma resposta bastante comum de plântulas. Esse mecanismo é denominado estiolamento (Franco \& Dillenburg 2007). As plantas na ausência de luz investem mais em crescimento de caules por alta atividade auxínica, porém, esse crescimento não resulta 
em um ganho real de massa seca visto que as plantas estão apenas respirando e gastando suas reservas (Carvalho et al. 2009). Esse crescimento compromete a sustentação da parte aérea, justificando assim a maior fragilidade das plântulas germinadas na ausência de luz. Assim, mesmo as sementes germinando em qualquer ambiente de luz (fotoblásticas neutras), e nesse experimento as plântulas apresentarem alta mortalidade no bioensaio na presença de luz, as plantas de pinhão-manso deverão se desenvolver melhor (apresentar maior vigor) quando crescidas em ambientes iluminados, como os locais de sua ocorrência natural: regiões semi-áridas, como savanas abertas (Putten et al. 2010).

Pelo crescimento rápido e boa adaptação a solos pobres (Sato et al. 2009), o pinhão-manso é utilizado como espécie pioneira na recuperação de áreas degradadas. Existem vários relatos de espécies pioneiras que germinam na sombra densa de floresta (por exemplo, Ricinodendron heudelotii (Baill.) Heckel - Euphobiaceae) (Kyereh et al. 1999), porém esses estudos costumam ser comprometidos, devido ao fato das mudas serem muito pequenas e morrerem rapidamente em baixa luminosidade. Por outro lado, a capacidade de sobrevivência de plantas germinadas sob reduzida disponibilidade luminosa aumenta com o tamanho da semente e com a expressão de caracteres morfológicos que promovem o crescimento em reduzida disponibilidade de luz (Franco \& Dillenburg 2007).

As plantas germinadas na presença de luz apresentaram crescimento mais lento, coloração esverdeada, cotilédones (quando surgidos) mais verdes e consistentes. A luz permitiu a realização de fotossíntese, com a abertura dos estômatos para a captação de $\mathrm{CO}_{2}$. A realização da fotossíntese aumenta as taxas de transpiração (Conti \& Tavares 2000) o que pode explicar a grande umidade observada na câmara de germinação durante o experimento com luz. A quantidade de água colocada nos recipientes com as sementes enroladas em papel de germinação pode ter contribuído para o aumento excessivo da umidade

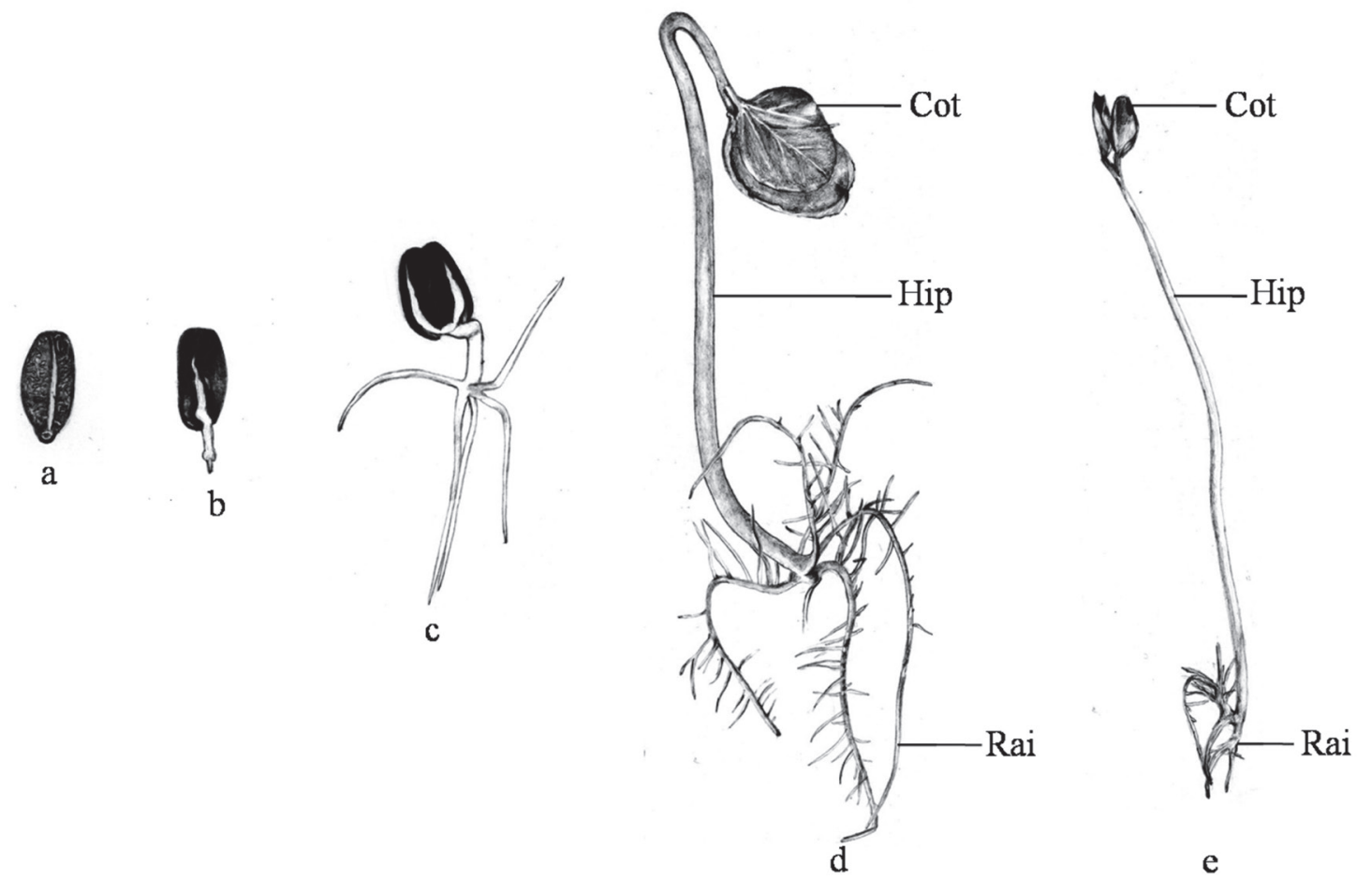

Figura 1. Morfologia da plântula de pinhão-manso (Jatropha curcas) germinada em câmara escura. a: semente embebida, b: rompimento do tegumento e protrusão da radícula, c: plântula com a raiz primária e as quatro secundárias, d: plântula com os cotilédones (6 dias após a germinação), e: plântula com os cotilédones abertos (11 dias após a germinação). Cot: cotilédones, Hip: eixo do hipocótilo, Rai: raízes. As figuras a-d estão em tamanho real, e a figura e cada centímetro da figura representa dois centímetros da plântula em tamanho real.

Figure 1. Seedling morphology in Jatropha curcas germinated in dark chamber. a: soaked seed, b: disruption of integument and radicle protrusion, c: seedling with the primary root and four secondary roots, d: seedling with cotyledons (6 days after the germination), e: seedling with open cotyledons (11 days after the germination). Cot: cotyledons, Hip: hypocotyl axis, Rai: roots. The figures a-d are in real size, and in the figure e every centimeter of the figure represents two centimeters in real size. 
dentro da câmara B.O.D. A umidade e a própria luz podem ser fatores que contribuíram para a morte das plântulas ao longo dos dias de germinação na presença de luz.

O término da expansão dos cotilédones ocorreu por volta do $7^{\circ}$ dia no experimento sem iluminação e $9^{\circ}$ dia no experimento com iluminação. A consistência das folhas cotiledonares na ausência de luz foi tenra e a coloração verde-esbranquiçada, enquanto as folhas cotiledonares das plântulas na presença de luz tinham a coloração verde mais intensa. Segundo Matos et al. (2011) a concentração de clorofilas totais atinge maior média em plantas de pinhão-manso que passam por fotoperíodo diário, explicando a coloração mais intensa nos cotilédones das plantas germinadas sob luz.

\section{Conclusão}

$\mathrm{O}$ experimento mostrou que na presença de luz existe uma homogeneização dos parâmetros germinativos em todos os lotes de sementes de pinhãomanso, o que não acontece na ausência de luz. Como a germinação foi semelhante, indiferente da presença ou não de luz, em todos os lotes de sementes, oriundos de diferentes localidades pode-se concluir que as sementes de pinhão-manso são fotoblásticas neutras.

O maior crescimento em tamanho das plântulas germinadas na ausência de luz pode ser explicado pela falta de um estimulo luminoso e, consequentemente, pelo estiolamento das plantas, o que não permite a planta seguir seu desenvolvimento normal, incluindo a não realização da fotossíntese. Os fatores que causaram o escurecimento do caule e a morte de plântulas, no experimento com luz, devem ser investigados para que esses fatores sejam eliminados e haja um aumento da eficiência na produção de mudas.

\section{Agradecimentos}

Os autores agradecem a FAPEMIG - Fundação de Amparo a Pesquisa de Minas Gerais, pelo apoio financeiro concedido ao projeto.

\section{Literatura citada}

Augustus, G.D.P.S, Jayabalan, M. \& Seiler G.J. 2002. Evaluation and bioinduction of energy components of Jatropha curcas. Biomass and Bioenerg 23: 161-164.

Añez, L.M.M., Coelho, M.F.B. \& Albuquerque, J.L.D.D. 2005. Caracterização morfológica dos frutos, das sementes e do desenvolvimento das plântulas de Jatropha elliptica Müll. Arg. (Euphorbiaceae). Revista Brasileira de Botânica 28:563-568.
Bandeira, A.S, Santos, J.L. \& Santos, D.L. 2011. Desenvolvimento inicial e acúmulo da biomassa de mudas de pinhão manso em diferentes condições de luminosidade. Cadernos de Agroecologia 6: 1-6.

Bewley, J.D. \& Black, M. 1994. Seeds: physiology of development and Germination. 2 ed. Plenum. New York.

Carvalho, C.A.L., Dantas, A.C.V.L., Pereira, F.A.C., Soares, A.C.F, Melo Filho, J.F. \& Oliveira, G.J.C. 2009. Tópicos em Ciências Agrárias, v. 1, Copyright, Bahia.

Conti, J.H. \& Tavares, F.C.A. 2000. Alterações fenotípicas em cultivares de alface selecionadas para calor. Horticultura Brasileira 18: 159-163.

Fanan S., Medina, P.F., Camargo, M.B.P. \& Ramos, N.P. 2009. Influência da colheita e do armazenamento na qualidade fisiológica de sementes de mamona. Revista Brasileira de Sementes 31: 150-159.

Ferraz, I.D.K. 1991. Germinação e armazenamento de sementes florestais de interesse econômico na Amazônia: problemas e necessidades de atuação. In: A.L. Val, R. Figliuolo \& E. Felberg (ed.). Bases científicas para estratégias de preservação e desenvolvimento da Amazônia: fatos e perspectivas. INPA, Manaus, 1: 225-229.

Ferri, M.G. 1983. Botânica: morfologia externa das plantas (organografia). Nobel, 15 ed. São Paulo.

Franco, M.A.S. \& Dillenburgl, L.R. 2007. Ajustes morfológicos e fisiológicos em plantas jovens de Araucaria angustifolia (Bertol.) em resposta ao sombreamento. Hoehnea 34: 135-144.

Gübitz, G.M., Mittelbach, M. \& Trabi, M. 1999. Exploitation of the tropical oil seed plant Jatropha curcas L. Bioresource Technology 67: 73-82.

Guerreiro, S.M.C. \& Gloria, B.A. 2003. Anatomia Vegetal, 3 ed., Viçosa.

Heller, J. 1996. Physic nut. Jatropha curcas L. Promoting the Conservation and use of Underutilized and Neglected Crops. I. Institute of Plant Genetics and Crop Plant Research, Gatersleben/International Plant Genetic Resources Institute.

Höfs, A., Schuch, L.O.B., Peske, S.T. \& Barros, A.C.S.A. 2004. Emergência e crescimento de plântulas de arroz em resposta à qualidade fisiológica de sementes. Revista Brasileira de Sementes 26: 92-97.

Kyereh, B., Swaine, M.D. \& Thompson, J. 1999. Effect of light on the germination of forest trees in Ghana. Journal of Ecology 87: 772-783.

Lopes, J.C., Capucho, M.T., Martins Filho, S. \& Repossi, P.A. 2005. Influência de temperatura, substrato e luz na germinação de sementes de bertalha. Revista Brasileira de Sementes 27: 18-24.

Loureiro, M.B.,Virgens, I.O., Núnes, I.A., Vilas-Boas, A.C., Teles, C.A.S., Castro, P.D.A., Drumond, M.A., Delmondez, R. \& Fernandez, L.G. 2007. Efeito do estresse hídrico sobre a germinação de sementes pinhãomanso (Jatropha curcas L.). Embrapa Semi-Árido, Petrolina, pp. 1-6. 
Matheus, M.T. \& Lopes, J.C. 2007. Morfologia de frutos, sementes e plântulas e germinação de sementes de Erythrina variegata L. Revista Brasileira de Sementes 29: 8-15.

Matos, F.S., Moreira, C.V., Missio, R.F. \& Dias, L.A.S. 2009. Caracterização fisiológica de mudas de Jatropha curcas L. produzidas em diferentes níveis de irradiância. Revista Colombiana de Ciências Hortícola 3: 126-134.

Matos, F.S., Gamboa, I., Ribeiro, R.P., Mayer, M.L., Neves, T.G., Leonardo, B.R.L. \& Souza, A.C. 2011. Influência da intensidade luminosa no desenvolvimento de mudas de Jatropha curcas L. Revista Agrarian 4: 265-272.

Melo, E., Pinto, J.E.B.P., Peixoto, J.R. \& Juliatti, F.C. 2001. Diferentes antioxidantes no controle da oxidação, germinação e desenvolvimento das plântulas na cultura in vitro de embriões da guarirobeira Syagrus oleracea (Mart.). Ciência Agrotécnica 25: 1301-1306.

Melo, M.F.F. \& Varela, V.P. 2006. Aspectos morfológicos de frutos, sementes, germinação e plântulas de duas espécies florestais da Amazônia. Revista Brasileira de Sementes 28: 54-62.

Ministério da Agricultura. 2009. Regra para a Análise de Sementes, Abastecimento e Pecuária, Brasília.

Nery, A.R., Rodrigues, L.N., Silva, P.D.F., Chaves, L.H.G., Dantas Neto, J. \& Gheyi, H.R. 2009. Crescimento do pinhão-manso irrigado com águas salinas em ambiente protegido. Revista Brasileira de Engenharia Agrícola e Ambiental 13: 551-558.

Nunes C.F., Santos D.N., Pasqual, M. \& Valente T.C.T. 2009. Morfologia externa de frutos, sementes e plântulas de pinhão-manso. Pesquisa Agropecuária Brasileira 44: 207-210.
Oliveira, E.C. 1993. Sementes florestais tropicais. ABRATES. Brasília.

Openshaw, K.A. 2000. A review of Jatropha curcas: an oil plant of unfulfilled promise. Biomass and Bioenergy 19: 1-15.

Peixoto, A.R. 1973. Plantas oleaginosas arbóreas. Nobel. São Paulo.

Putten E, Franken Y.J., Jongh J. 2010. General data on Jatropha. In: J. Jongh (ed.). The Jatropha handbook: from cultivation to application. Netherlands. Fact Foundation, pp. 1-7.

Rossatto, D.R. \& Kolb, R.M. 2010. Germinação de Pyrostegia venusta (Bignoniaceae), viabilidade de sementes e desenvolvimento pós-seminal. Revista Brasileira de Botânica 3: 51-60.

Sato, M., Bueno, O.C., Esperancinl, M.S.T. \& Frigo, E.P. 2009. A cultura do pinhão-manso (Jatropha curcas L.): uso para fins combustíveis e descrição agronômica. Revista Varia Scientia 7: 47-62.

Tagliani, M.C. \& Ribas, K.C.Z. 2009. Germinação de sementes de pinhão manso (Jatropha curcas L.) sob diferentes substratos e temperaturas. I Congresso brasileiro de pesquisas de Pinhão-manso, pp.1-4.

Tiwari, A.K., Rahman, H. \& Kumar, A. 2007. Biodiesel production from jatropha oil (Jatropha curcas) with high free fatty acids: an optimized process. Biomass and Bioenergy 31: 569-575.

Zamith, L.R. \& Scarano, F.B. 2004. Produção de mudas de espécies das Restinga do município do Rio de Janeiro, RJ, Brasil. Acta Botanica Brasilica 18: 161-176.

Zar, J.H. 1999. Biostatistical analysis. Prentice-Hall, New Jersey. 